\title{
Perceções sobre criatividade: Estudo com estudantes do Ensino Superior
}

\author{
Maria de Fátima Moraisi \& Leandro S. Almeidaii \\ Universidade do Minho, Portugal
}

Resumo

No mundo atual, a universidade tem um papel crucial na formação de cidadãos capazes de inovar. A criatividade surge, assim, como um conceito a valorizar no ensino superior, mas tal valorização implica alterações no quotidiano educativo. Uma fonte de informação relevante para a rentabilizações das competências criativas nos alunos universitários é auscultar o que estes pensam sobre elas. Neste sentido, a partir do questionário "Universidade e Competências Criativas", foram analisadas perceções de 582 estudantes de uma universidade portuguesa acerca da conceituação e da valorização de criatividade no contexto académico. As percepções foram analisadas em função da área curricular de formação e do género, encontrando-se diferenças estatisticamente significativas para ambas as variáveis. Os resultados permitem reflexões no sentido de aprofundamentos futuros deste estudo, assim como apontam direções para cuidados e reforços a ter nas práticas educativas neste nível de ensino.

Palavras-chave

Criatividade; Ensino Superior; Estudantes universitários; Perceções

\section{Introdução}

Criatividade, num universo de múltiplas definições (Barbot, Besançon, \& Lubart, 2011; Morais, 2013), reporta-se a ideias ou produtos simultaneamente originais e eficazes num contexto e momento sócio-histórico 
(Runco \& Jager, 2012). Permite a resolução de problemas no quotidiano e não só a rutura de paradigmas (Craft, 2005), havendo um potencial criativo a desenvolver em todos os indivíduos (Runco, 2014) e sendo as competências criativas modificáveis (Ma, 2006). Sublinha-se ainda a criatividade como um dos mais importantes requisitos para a inovação (Lubart \& Zesnani, 2010).

O papel essencial da criatividade na inovação faz com que seja uma das competências mais reclamadas na atualidade. Se a importância deste constructo, para o indivíduo e para a sociedade, é destacada há mais de meio século (Guilford, 1950), e se partir daí tem sido alvo de investimento por académicos e profissionais (Isaksen \& Akkermans, 2011), é hoje uma necessidade à sobrevivência (Caniels, 2013) ou uma competência do século XXI (Miller \& Dumford, 2014). Não mais é reclamada essencialmente pelo e para o contexto educativo, sendo-o globalmente para a resposta inovadora às exigências da economia, dos avanços tecnológicos, do surgimento de novos mercados, serviços e necessidades sociais (Sahlberg, 2011; Smith-Bingham, 2007).

Num mundo em que a mudança é a constante, a velocidade é o ritmo e, muitas vezes, a imprevisibilidade é a certeza, não é mais suficiente reproduzir e aplicar soluções. É necessário arriscar lucidamente e criar criticamente (Kim \& Hull, 2012; McWilliam, 2008). Como diz Craft (2007), é cada vez mais relevante identificar problemas e oportunidades que outros não identificam. Só este desafio à resolução criativa de problemas, num hoje pressionado por futuro, responderá à qualidade de vida pessoal, reinventada frequentemente, promovendo indivíduos mais pró-ativos, confiantes e persistentes, assegurando maior bem-estar pessoal no meio social (Cropley, 2009).

O foco deste artigo está num contexto educativo. Então, a aprendizagem necessariamente terá de captar radicais alterações, pois tornase agora incompatível com estabilidade, linearidade ou mesmo continuidade. Mais especificamente, a universidade toma um papel central na urgência atual e global de inovação (Chen \& Chen, 2012; MacLaren, 2012). O economista Richard Florida, na obra The rise of the creative class (2002), alerta o ensino superior para alterações nas suas prioridades educativas com consequências no currículo. Mais tarde, em The flight of the creative class (Florida, 2005), liga criatividade à inovação tecnológica e à prosperidade económica fundamentais ao presente e ao futuro, reafirmando a universidade como local indiscutível de preparação para a resolução criativa dos problemas. Também Gibson (2010) 
fala em "mandatos poderosos às universidades de todo o mundo para que promovam criatividade nos seus alunos" (p. 607). Este e outros autores (Barak, 2009; Deverell \& Moore, 2014) sublinham a necessidade de o ensino superior fomentar características como a tomada de risco, a autonomia, a flexibilidade, a abertura à experiência, a espontaneidade, sendo espaço encorajador e, de facto, formador face ao mundo de trabalho. A universidade tem de ser um campus criativo (Pachucki, Lena, \& Tepper, 2010) para a força de trabalho futura altamente especializada que liderará todos os domínios da vida social (Gibson, 2010; McWilliam, Hearn, \& Haseman, 2008).

A resposta a estas necessidades passa, então, pela ênfase na flexibilidade do desenho curricular e das metodologias de ensino e avaliação. Estas devem apelar à diversidade de conhecimentos, perspetivas e tarefas, à sintonia dos conteúdos e das estratégias com os interesses dos alunos e da sociedade, ao estudante curioso, crítico, autorregulado, autoconfiante e motivado (Masetto, 2012; McWilliam, 2008). Tal flexibilização deve permitir que o estudante possa reconhecer, valorizar e aplicar as suas competências criativas (Jackson \& Sinclair, 2007).

Alguns autores vão especificando tarefas e técnicas para o objetivo anterior ser operacionalizável - por exemplo, valorizar ensaios e outras formas de escrita, portefólios, estudos de caso, role-playing e outras performances, posters e outras formas de apresentação pública, sempre enfatizando a oportunidade do debate (e.g., Balchim, 2007; Cropley \& Cropley, 2009). Vale a pena sublinhar o comentário de McWilliam (2008) no sentido de que o uso, tão estimulado, de novas tecnologias nem sempre serve novas ideias, muitas vezes suportando apenas velhas práticas e não sendo mais do que novas roupagens para a power point tradition referida por Nordstrom e Korpelainen (2011).

Porém, outras contribuições enfatizam mudanças mais globais e mais subjetivas também. As atitudes e a atuação do docente, na aula e fora dela, são vistas como essenciais para o ensino superior cumprir a missão de preparar os alunos para a criatividade. Deve perder-se menos tempo com instruções e ser mais co-worker, perder-se menos tempo a minimizar riscos e confrontar mais com ambiguidades e problemas, perder-se menos tempo a vigiar e ter mais tempo a planificar e alterar (McWilliam, 2008). Também não pensar tanto no erro ou na ignorância como lacuna, mas como algo que pode 
criar conhecimento é referido por McWilliam e colegas (2008), rentabilizando, para Leadbeater (2000), uma ignorância útil para a aprendizagem ser espaço de conexões flexíveis e não rotinizadas. Não tem, assim, de haver um plano definido, materializado em detalhes, nem tem de haver culpados ou exultados, para que a criatividade seja promovida neste espaço educativo: isso, aliás, seria incompatível com a complexidade que tal objetivo exige (Tosey, 2007). Há que criar condições no local para criatividade acontecer e isto, mais uma vez para Tosey (2007), não se trata de um compromisso técnico - envolve valores, poderes, conflitos e riscos.

A defesa da criatividade no ensino superior implica alterações profundas nas políticas e no processo de ensino-aprendizagem. É assim compreensível que, paralelamente a este discurso científico, pedagógico, e mesmo político, de defesa inquestionável do fomento da criatividade pelas universidades como resposta ao mundo atual, surjam aparentes paradoxos traduzidos em obstáculos a esse mesmo discurso. "As práticas na universidade precisam de ser mais criativas", como referem Deverell e Moore (2014, p. 2). O ensino superior parece não estar, de facto, a valorizar a resolução criativa de problemas - no seu dia-a-dia e, consequentemente, em quem prepara.

A universidade continua a reproduzir modelos tradicionais de lecionação e de avaliação. Ora, cada vez mais a transmissão de saberes se torna anacrónica num mundo que não mais é previsível e ao qual cada estudante tem acesso imediato (Pink, 2005). Como refere McWilliam (2008, p. 267), "a posição do aluno aos pés do guru" é indefensável numa era digital e global, tendo a universidade a missão de treinar a capacidade de editar a realidade. Também a avaliação sumativa, coerente com a lecionação transmissiva, é um dos elementos mais prejudiciais à criatividade no ensino superior (Balchim, 2007; Miller \& Dumford, 2014).

Mitos, conceções erradas mas frequentes, sobre criatividade - como as do génio isolado, da inspiração súbita, do talento inato ou da mera originalidade - têm contribuído para que este conceito não seja valorizado nas universidades (MacLaren, 2012), provocando mesmo tensões face a valores tradicionais da academia como rigor, respeitabilidade, conformidade ou produção quantificável (Tosey, 2007). Também a maioria dos docentes não domina técnicas sobre criatividade (Jackson, 2007), havendo ainda inconsistência na sua concetualização (Edwards, McGoldrick, \& Oliver, 2007). 
A cultura do medo e da precaução parece dominar o ensino superior, eliminando a tomada de riscos e a autonomia, em professores e alunos (Hargreaves, 2008). O contexto sócio-político atual pode também não ajudar, dado o reforço neoliberal à produtividade (Clegg, 2008; MacLaren, 2012). Assim, para estes autores, pressões para a eficácia, captação de fundos, produção, controlo permanente das tarefas, insegurança na manutenção do trabalho, podem criar insegurança e conformismo incompatíveis com o ato de criar. Para MacLaren (2012), não existem mesmo, na universidade atual, os requisitos básicos que Hennessey \& Amabile (2010) pressupõem para a criatividade se desenvolver. $\mathrm{O}$ ensino superior vive então uma ambiguidade entre regras burocráticas, convenções, pedidos económicos externos, e uma educação necessária de mentes livres, críticas e criativas (Clegg, 2008).

Auscultar, neste cenário, o que os alunos pensam e como valorizam criatividade emerge como fundamental (Sadeghi \& Ofoghi, 2011; Sathler \& Fleith, 2010). Como expressa Gibson (2010), é necessário ouvir "a voz dos estudantes" (p. 611). Há, porém, necessidade de mais investigações sobre o tópico a nível atual e internacional (Pachucki et al., 2010; Slate, LaPrairie, Schulte, \& Onwuegbuzie, 2011). Oliver, Shah, McGoldrick, e Edwards (2007) mostram dificuldades dos alunos em explicar criatividade, havendo hesitações e inconsistências nas suas respostas. Porém, surge nos estudantes como algo a valorizar (Dineen, 2007; Oliver et al., 2007), apesar de algum conformismo e resistência à novidade, percepcionada como mais complexa (Edwards et al., 2007; Oliveira \& Alencar, 2007).

Sabe-se ainda que perceções de alunos sobre obstáculos à expressão criativa e sobre criatividade em práticas docentes variam com a área curricular e o género. Por exemplo, as Artes parecem ser mais favoráveis à manifestação de criatividade para Cropley e Cropley (2009), mas menos do que Ciências para Hosseini (2011) ou Morais, Almeida, e Azevedo (2014). Ribeiro e Fleith (2007) mostram perceções mais positivas nas Humanidades face às Ciências sobre práticas criativas. Quanto ao género, Alencar (2001) mostrou que os rapazes perspetivam como maior obstáculo à criatividade a falta de motivação, enquanto as raparigas elegem a repressão social. Num estudo transcultural, Alencar, Fleith, e Martinez (2003) afirmam a inibição ou timidez nos rapazes como maior barreira à criatividade no ensino superior. Ambos os estudos relacionam estes dados sobre a criatividade com papéis e 
expectativas sociais que, ao longo da vida, vão modelando atitudes e comportamentos diferentemente em ambos os géneros. Será então esperável que também perceções sobre o conceito de criatividade e sua valorização oscilem com tais variáveis.

Face ao exposto, este artigo analisa como alunos universitários concetualizam e valorizam a criatividade no contexto académico. Estas perceções são analisadas globalmente, mas também em função da área curricular e do género dos estudantes. Os dados poderão ajudar a identificar dificuldades e potencialidades no que respeita à criatividade na universidade portuguesa.

\section{Método}

\section{Participantes}

Participaram no estudo 582 alunos de uma universidade pública portuguesa. As áreas curriculares frequentadas eram Artes e Humanidades (AH) - cursos de Línguas e Literaturas, Estudos Portugueses e Lusófonos, Música, Arquitetura e Comunicação de Moda (27\%); Ciências e Tecnologias (CT) - cursos de Matemática, Estatística, Física, Bioquímica e Engenharias (36\%); e Ciências Sociais e Humanas (CSH) - cursos de Educação, Psicologia e Ciências da Comunicação (37\%). Na amostra, 59\% eram raparigas e $41 \%$ rapazes, sendo $63 \%$ alunos do $2^{\circ}$ ano de licenciatura e $37 \%$ do $1^{\circ}$ ano de mestrado. A média de idades é 23,4 anos, oscilando entre $18 \mathrm{e}$ 59. Na Tabela 1 é indicada a caracterização dos participantes, tomando a área curricular e o género.

\begin{tabular}{lccc}
\hline Área curricular de formação & N & Masc. & Fem \\
\hline Artes \& Humanidades & 157 & 70 & 87 \\
Ciências e Tecnologias & 212 & 129 & 83 \\
Ciências Sociais e Humanas & 213 & 38 & 175 \\
Total & 582 & 237 & 345 \\
\hline
\end{tabular}

Tabela 1 - Dados descritivos dos participantes 


\section{Instrumentos}

No contexto de uma pesquisa acerca de perceções de criatividade nas práticas docentes (Morais, Almeida, Azevedo, Alencar, \& Fleith, 2014), aplicou-se um questionário, intitulado "Universidade e Competências Criativas", para avaliar a conceituação e valorização da criatividade no ensino superior. As perguntas do questionário foram previamente revistas por um investigador em criatividade para avaliar a relevância das suas questões, as quais foram ainda respondidas por um pequeno grupo de 10 alunos para avaliar a sua compreensão e processos de resposta. Trata-se de (i) 4 questões para resposta em escala likert de 5 pontos (entre discordo plenamente a concordo plenamente), como "Até que ponto acha importante que a universidade proporcione contextos intencionais de promoção da criatividade nos alunos/nos docentes?"; "Até que ponto acha importante serse criativo para um bom desempenho na universidade/no contexto de trabalho fora da universidade?"); (ii) uma questão de resposta dicotómica (sim/não) acerca da motivação pessoal para participar num curso promocional ("Gostaria de frequentar um contexto intencional de promoção da criatividade, p. ex. um curso breve, workshops,...?"); (iii) duas questões sobre a abordagem dos conceitos criatividade/inovação e sobredotação no percurso universitário ("Já abordou, em alguma Unidade Curricular do seu percurso universitário, o conceito de...."), com resposta dicotómica (sim/não); e iv) uma questão sobre a relevância de constructos (aptidões, motivação, conhecimento e emoções) na criatividade ("exemplo: "Aptidões são... para a criatividade") usando escala tipo likert de resposta com 4 pontos (entre "nada ou muito pouco importante(s)" e "muito importante(s)").

\section{Procedimento}

Foram contactados professores universitários para a autorização da aplicação do instrumento nas suas turmas. Os alunos responderam ao questionário na sala de aula, estando o docente presente na aplicação, demorando o seu preenchimento cerca de 10 minutos. O instrumento foi aplicado por psicólogas. Foi explicado, sucintamente, o objetivo da pesquisa e garantido o anonimato dos alunos no início da recolha de dados, enquanto requisitos prévios ao seu consentimento informado para participarem no estudo. Na análise dos dados recorreu-se ao programa IBM SPSS, versão 22.0 para Windows. 


\section{Resultados}

Começa-se por apresentar na Tabela 2 a distribuição de respostas em percentagens face à conceituação de criatividade a partir de quatro dimensões a avaliar. Verifica-se algumas ausências de resposta nestes itens.

\begin{tabular}{lrrrc}
\hline Itens/classificações & $\mathbf{1}$ & $\mathbf{2}$ & $\mathbf{3}$ & $\mathbf{4}$ \\
\hline Criatividade apela a aptidões & $23.9 \%$ & $29.0 \%$ & $23.4 \%$ & $15.1 \%$ \\
Criatividade apela a motivação & $13.2 \%$ & $18.2 \%$ & $26.5 \%$ & $33.5 \%$ \\
Criatividade apela a conhecimento & $17.4 \%$ & $27.3 \%$ & $28.5 \%$ & $18.0 \%$ \\
Criatividade apela a emoções & $36.6 \%$ & $16.8 \%$ & $13.1 \%$ & $24.7 \%$ \\
\hline
\end{tabular}

\section{Tabela 2 - Distribuição de percentagens de resposta face à} conceituação de criatividade

Verifica-se dispersão nas respostas para todos os itens, tomando as quatro dimensões. Porém, pode destacar-se a valorização da motivação (60\% de afirmações como sendo "importante" e "muito importante") e desvalorização das aptidões e das emoções (52,9\% e 53,4\%, respetivamente, de respostas importante" [1] e "pouco importante" [2]). A partir de uma ANOVA, foram analisadas diferenças entre médias em função da área curricular e do género. No primeiro caso, verificou-se uma diferença estatisticamente significativa entre $\mathrm{CSH}$ e $\mathrm{AH}$ face à presença de aptidões na criatividade $(F(2,531)=3.214, p=.041)$, obtendo-se valor mais elevado em $\mathrm{CSH}(M=2.44, D P=1.08)$ do que em AH $(M=2.15, D P=1.05)$. Também face às emoções, emergiu uma diferença significativa $(F(2,530)=5.628, p=.004)$, valorizando-as mais $\mathrm{CSH}(M=2.37, D P=1.21)$ do que $\mathrm{CT}(M=2.06, D P=$ 1.27) e $\mathrm{AH}(M=2.49, D P=1.23)$. No que respeita ao conhecimento, a diferença surgida $(F(2,530)=4.236, p=.015)$ mostra valorização superior por CT $(M=2.63, D P=.95)$ face a CSH $(M=2.35, D P=1.00)$. No caso da variável género, apenas foi encontrada uma diferença estatisticamente significativa $(t(529)=2.778, p=.006)$, ilustrando que os rapazes $(M=2.67$, $D P=1.01)$ valorizam, mais do que as raparigas $(M=2.42, D P=1.00)$, o conhecimento no conceito de criatividade.

Após os dados sobre a conceituação de criatividade, apresentam-se os relativos à sua valorização. Tomando uma análise descritiva com recurso 
às médias $(\mathrm{M})$, desvios-padrão (DP), valores mínimos e máximos, são apresentadas na Tabela 3 as perceções dos alunos sobre a importância/valorização de criatividade no contexto académico.

\begin{tabular}{llcccc}
\hline Dimensões & & M & DP & min & max \\
\hline $\begin{array}{l}\text { Importante ser-se criativo para bom desempenho } \\
\text { académico na universidade? }\end{array}$ & 577 & 4.28 & .85 & 1 & 5 \\
$\begin{array}{l}\text { Importante ser-se criativo no contexto de trabalho } \\
\text { fora da universidade? }\end{array}$ & 577 & 4.60 & .60 & 1 & 5 \\
$\begin{array}{l}\text { Importante universidade proporcionar promoção } \\
\text { de criatividade para alunos? }\end{array}$ & 566 & 4.49 & .78 & 1 & 5 \\
$\begin{array}{l}\text { Importante universidade proporcionar promoção } \\
\text { de criatividade para docentes? }\end{array}$ & 576 & 4.51 & .27 & 1 & 5 \\
\hline
\end{tabular}

\section{Tabela 3 - Análise descritiva dos resultados sobre a valorização da} criatividade no contexto académico

Pode verificar-se que em todos os itens se observa uma pontuação média tradutora de grande relevância dada à criatividade, sendo ligeiramente inferior a associada ao bom desempenho académico. Os valores mínimos e máximos indicam boa distribuição de resultados. No que respeita a percentagens de respostas, numa análise mais detalhada, verifica-se que i) 86.4\% afirmam com classificações de concordância (46.2\%) e de concordância plena (40.2\%) a importância da criatividade face a um bom desempenho; ii) $94.7 \%$ fazem-no face ao trabalho fora da universidade (29.9\% "'"concordando" e 64.8\% "concordando plenamente"); iii) $87.1 \%$ valorizam contextos intencionais de promoção da criatividade na universidade face aos alunos (26.6\% "concordando" e 60.5\% "concordando plenamente"); e iv) $86.4 \%$ fazem-no face aos docentes (28.5\% em "concordância" e $57.9 \%$ em "concordância plena"). Exceto no que respeita ao desempenho académico, mais de $50 \%$ se coloca nos níveis 4 e 5 de resposta ("concordo e "concordo plenamente") face à valorização da criatividade inquirida.

Especificando a análise por área académica, mostra-se na Tabela 4 as médias (M) e desvios-padrão (DP). Todos os itens traduzem elevada valorização da criatividade no ensino superior, não havendo valores médios 
inferiores a 4 e sendo alguns superiores a 4.50. Observa-se uma valorização menos elevada por $\mathrm{CT}$ em todos os itens. $\mathrm{Na}$ apreciação de contextos de promoção aos docentes por parte de $\mathrm{AH}$, surge um valor elevado de desviopadrão, quase igual ao da média, denotando grande disparidade de opiniões.

\begin{tabular}{llccc}
\hline & & AH & CT & CSH \\
& & $(\mathbf{n = 1 5 7 )}$ & $\begin{array}{c}(\mathbf{n = 2 1 2}) \\
(\mathbf{n = 2 1 3})\end{array}$ \\
\hline Importante ser-se criativo para bom desempenho académico & $\mathrm{M}$ & 4.33 & 4.18 & 4.34 \\
na universidade? & $\mathrm{DP}$ & .89 & .81 & .84 \\
Importante ser-se criativo no contexto de trabalho fora da & $\mathrm{M}$ & 4.65 & 4.54 & 4.64 \\
universidade? & $\mathrm{DP}$ & .56 & .63 & .61 \\
Importante a universidade proporcionar promoção da & $\mathrm{M}$ & 4.54 & 4.37 & 4.56 \\
criatividade para alunos? & $\mathrm{DP}$ & .77 & .83 & .70 \\
Importante a universidade proporcionar promoção da & $\mathrm{M}$ & 4.79 & 4.24 & 4.58 \\
criatividade para docentes? & $\mathrm{DP}$ & 4.16 & .87 & .65 \\
\hline
\end{tabular}

Tabela 4 - Análise descritiva dos resultados sobre valorização da criatividade no contexto académico em função da área curricular

Realizou-se uma ANOVA para analisar as diferenças de médias nas respostas a estas questões, apenas emergindo uma diferença estatisticamente significativa no que respeita à necessidade de contextos de promoção de competências criativas dirigidos a alunos $(F(2,565)=3.485, p$ $=.031$ ), afirmando mais esta necessidade os alunos de CSH face aos colegas de CT.

Apresenta-se agora a análise descritiva por género dos alunos na Tabela 5. Em todos os itens, ambos os géneros expressam grande valorização da criatividade (oscilação de valores entre 4.19 e 4.68). Note-se o desvio-padrão elevado na apreciação pelos rapazes da promoção face aos docentes, ilustrando grande dispersão de opiniões.

Numa ANOVA, para analisar diferenças de médias por género, surgiram três dados estatisticamente significativos. As raparigas valorizam mais criatividade face ao desempenho académico $(t(575)=-2.109, p=.035)$, ao trabalho fora da universidade $(t(575)=-3.708, p=.000)$ e à promoção nos alunos $(t(564)=-2.599, p=.010)$. 


\begin{tabular}{llcc}
\hline & & $\begin{array}{c}\text { Masc. } \\
(\mathbf{n}=\mathbf{2 4 5})\end{array}$ & $\begin{array}{c}\text { Femin. } \\
(\mathbf{n}=\mathbf{3 3 7})\end{array}$ \\
\hline Importante ser-se criativo para bom desempenho académico na & $\mathrm{M}$ & 4.19 & 4.34 \\
universidade? & $\mathrm{DP}$ & .86 & .84 \\
Importante ser-se criativo no contexto de trabalho fora da & $\mathrm{M}$ & 4.49 & 4.68 \\
universidade? & $\mathrm{DP}$ & .68 & .53 \\
Importante a universidade proporcionar promoção da criatividade & $\mathrm{M}$ & 4.38 & 4.55 \\
para alunos? & $\mathrm{DP}$ & .82 & .73 \\
Importante a universidade proporcionar promoção da criatividade & $\mathrm{M}$ & 4.48 & 4.53 \\
para docentes? & $\mathrm{DP}$ & 3.44 & .74 \\
\hline
\end{tabular}

Tabela 5 - Análise descritiva dos resultados sobre valorização da criatividade no contexto académico em função do género

Nos itens de resposta dicotómica à questão "Gostaria de frequentar um curso de promoção de criatividade?", 83.5\% dos alunos responderam sim. Verificou-se ainda, pelo teste qui-quadrado, associação significativa entre este item e a área curricular $(\chi 2(4)=14.496, p=.006)$, negando mais os alunos de CT essa intenção (52.4\%). Também se verificou associação significativa deste item ao género $(\chi 2(1)=18.160, p=.000)$, afirmando mais as raparigas vontade de frequência de um curso promocional (63.4\%).

Acerca da abordagem curricular dos conceitos "criatividade/inovação", 47.4\% dos alunos negam tal abordagem e 51\% afirmam-na. Face ao conceito de "sobredotação", apenas $13.4 \%$ dos alunos afirmam a abordagem curricular do mesmo, negando-a 85.2\%. Há uma associação estatisticamente significativa face à área curricular $(\chi 2(4)=23.668, p=.000)$, mostrando CSH mais afirmações positivas $(40.7 \%)$ e CT mais negações $(46.4 \%)$. Para a abordagem do conceito "sobredotação" $(\chi 2(42)=56.009, p=.000)$, as CSH mostraram mais respostas afirmativas (74.4\%). Não se evidenciaram associações estatisticamente significativas, nestes itens, face ao género.

\section{Discussão}

Numa sociedade marcada pela mudança e pela imprevisibilidade em todos os domínios, a Universidade tem um papel crucial na formação de cidadãos capazes de inovar (Gibson, 2010; Pachucki et al., 2010). Porém, 
essa função implica alterações nas políticas educativas e no quotidiano do ensino/aprendizagem (Nordstrom \& Korpelainen, 2011), vivendo atualmente a universidade um paradoxo entre a necessidade de formar alunos para a criatividade e a continuidade com rotinas e valores há muito tempo enraizados.

Apesar de emergirem cada vez mais investigações e reflexões sobre as competências criativas no ensino superior (Cropley \& Cropley, 2009; Jackson, Oliver, Shaw, \& Wisdom, 2007), ainda é um tópico pouco estudado (Kleiman, 2008), face ao qual é relevante aumentar o investimento, nomeadamente escutando a perspetiva dos alunos (Sadeghi \& Ofoghi, 2011; Slate et al., 2011).

Os resultados obtidos sugerem alguma dispersão nas respostas dos alunos por diferentes componentes deste constructo, não acontecendo tanto face à motivação, mas havendo mesmo polarização de opiniões quanto ao conhecimento. Nota-se ainda desvalorização das aptidões e das emoções. Ora, o conhecimento é fundamental para a criatividade (Sternberg, 2015), assim como as emoções (Davis, 2009) e as aptidões (Baer, 2010). Então, aparecer a motivação como a dimensão mais associada à criatividade parece positivo, já que pode apontar para a aposta num conceito passível de desenvolvimento, assim como é coerente com o papel crucial que a investigação atribui a tal variável (Hennessey \& Amabile, 2010). Contudo, essa dimensão volitiva na perspetiva de criatividade também deveria espelhar-se no reconhecimento da importância do conhecimento (rentabilizável no mundo académico por excelência), das emoções (tomando o desenvolvimento pessoal e interpessoal) e mesmo das competências (face à modificabilidade permitida por intervenções intencionais).

Também nos trabalhos de Oliver e colaboradores (2007) e de Walker e Gleaves (2008), tomando alunos universitários, surgiram hesitações, dispersões, mesmo inconsistências e erros na definição de criatividade. Os resultados que não se inserem nas teorias explícitas de criatividade podem, assim, relacionar-se com conceções inseguras ou falsas sobre este constructo difícil de reunir consensos (Simonton, 2012) e frequentemente influenciado por mitos (Montuori, 2011). Também poderá não ser alheio a estas dificuldades o facto de cerca de metade da amostra referir não ter curricularmente abordado a criatividade e mais de $85 \%$ o fazer face ao 
conceito de sobredotação que a implica (Renzulli, 2005). Neste sentido ainda, Oliver e colegas (2007) mostram a reclamação dos estudantes face a não ser habitual a abordagem e a discussão da criatividade.

Por seu lado, em vários itens do questionário emergiu grande valorização da criatividade pelos estudantes. Mais de $80 \%$ destes alunos consideram como "importante" ou "muito importante" a criatividade para um bom desempenho académico e para o trabalho profissional futuro, assim como cursos promocionais de competências criativas na universidade, quer para alunos quer para docentes, tendo ainda afirmado o desejo de frequentar um desses cursos. Esta valorização está de acordo com poucos estudos feitos neste domínio (Dineen, 2007; Oliver et al., 2007; Walker \& Gleaves, 2008). É, porém, de notar que a associação da criatividade ao desempenho escolar foi ligeiramente inferior à realizada face ao trabalho fora da universidade. No estudo de Walker e Gleaves (2008) é referido mesmo um conflito entre ser criativo e obter boas classificações escolares, dado também constatado em alguns estudantes por Oliver e colegas (2007), mencionando estes frustração e tensão entre ser criativo e ser académico. Apesar do resultado obtido na amostra portuguesa poder ser encarado nessa tensão, comparativamente é um dado bem mais otimista.

Tomada a área curricular, verifica-se menor valorização significativa pelas $\mathrm{CT}$, em contraste com $\mathrm{CSH}$, face à necessidade de formação em criatividade para alunos. Também são os alunos de CT que menor vontade manifestam em participar num contexto de treino de competências criativas. Por sua vez, estes dados parecem coerentes com os resultados face à abordagem curricular dos conceitos de "criatividade/inovação" e de "sobredotação": verifica-se que são as CSH que mais afirmam a abordagem de tais conceitos e as CT que mais negam a abordagem da "criatividade/inovação".

Assim, a maior valorização da criatividade no contexto académico pelas $\mathrm{CSH}$ face às $\mathrm{CT}$ parece compreensível, pensando que no primeiro caso os alunos lidarão mais frequentemente com divergência de opiniões, crítica ou perspetivação além da realidade quotidiana, sendo talvez implicada maior reflexão ou imaginação. No contexto universitário, e mesmo pré-universitário, propostas de trabalho como ensaios, debates, role-playings ou entrevistas serão mais frequentes nesta área (por exemplo, em Psicologia, Comunicação 
ou Educação) do que nas CT. Ora, tal tipo de tarefas explicita e facilita a expressão criativa (Edwards et al., 2007). Também uma maior abordagem académica de conteúdos como criatividade, inovação ou sobredotação podem reforçar uma maior valorização da criatividade. Alunos de CT serão talvez confrontados no quotidiano académico com uma resolução de problemas mais concreta e objetiva (e.g., problemas numéricos, mecânicos, laboratoriais), valorizando mais um pensamento convergente e não tanto a explicitação de competências criativas, as quais podem ainda necessitar de ser desmistificadas dada a sua relevância para a investigação científica e tecnologia (Wood \& Bilsborow, 2014).

É curioso verificar que são as $\mathrm{AH}$ que mais expressam divergência de opinião perante a promoção de criatividade nos docentes. O estudo de Morais, Almeida, e Azevedo (2014) mostra-nos pior perceção destes alunos, face a colegas de outras áreas, relativamente a dimensões relacionais das práticas docentes que podem promover criatividade, como o clima para a expressão dos alunos ou o interesse pela aprendizagem dos mesmos. Por seu lado, o estudo ilustra que estes alunos de AH apenas não manifestaram as piores perceções sobre criatividade nas práticas docentes face a metodologias de ensino e avaliação, contrastando - com os colegas de CT com alunos de $\mathrm{CSH}$. Recordando um apelo mais explícito à manifestação de criatividade no contexto académico nas Artes (Edwards et al., 2007; Morais, 2001) e a maior associação da criatividade a este domínio no senso comum (Cropley, 2009), pode hipotetizar-se uma maior exigência destes alunos face à criatividade no ensino, mas manifestando-se tal exigência dividida entre dimensões mais relacionais e curriculares (e eventualmente operacionalizando-se, mais ou menos, na perceção de necessidades de formação por parte dos docentes).

Quanto à variável género, as raparigas demonstram maior valorização de criatividade face ao desempenho académico, ao trabalho fora da universidade, quando encaram a promoção nos alunos e a frequência pessoal de um curso promocional. Sendo esta variável muito influenciada ao longo de toda a vida por dimensões psicossociais (Caleo \& Heilman, 2014), compreende-se que influencie representações e, por consequência, as de criatividade no ensino superior. Por influência de estereótipos desde a infância, o género feminino surge como mais conformista, correndo menos 
riscos, sendo menos empreendedor e tendo menos autoestima (Shinnar, Giacomin, \& Janssen, 2012). Coerentemente, surge também como tendo menos oportunidades face à expressão criativa (Gralewski \& Karwowski, 2013; Kemmelmeier \& Walton, 2012). Estas manifestações diferenciais podem então explicar uma maior necessidade assumida de competências criativas (e, consequentemente, sua maior valorização) por parte das raparigas no nível de preparação para o futuro pessoal e profissional que é a universidade por excelência. Resta a curiosidade de os rapazes manifestarem maior dispersão de opiniões face à promoção de criatividade nos docentes, não sendo contudo este dado estatisticamente significativo.

O estudo apresenta limitações. A amostra poderia ser maior e, sobretudo, ser constituída por alunos de instituições diferentes. Alencar e Fleith (2001) mostraram diferenças nas perceções de estudantes em função do tipo de universidade. Também a avaliação foi feita a partir de autorrelatos, havendo nela sempre desejabilidade social (Moscovici, 2003). Nesta avaliação, o questionário usado poderá ainda ser revisto de forma a haver maior coerência entre a formulação das questões iniciadas por "até que ponto acha importante" e o critério de resposta gradativa de "discordo completamente" até "concordo completamente"; porém, tal formulação não causou qualquer dúvida aos estudantes, nem no estudo-piloto, nem na administração à amostra, não parecendo ter invalidado resultados. Note-se, por seu lado, que autores como Walker e Gleaves (2008) ou Oliver e colegas (2007) referem ambiguidades nas opiniões face à criatividade no contexto universitário. Porém, esta primeira auscultação poderá potencialmente ser útil numa área muito pouco pesquisada, mesmo internacionalmente. Desmistificar criatividade surge como relevante, tal como em outros estudos (Oliver et cols., 2007; Walker \& Gleaves, 2008), nomeadamente havendo uma abordagem explícita do tema (incluindo a abordagem curricular). Esta necessidade apareceu aqui mais enfatizada face às CT. Também a universidade poderá ser um local privilegiado para destruir estereótipos com consequências nefastas para a expressão criativa, particularmente encarando o género feminino. Face a estas preocupações, os docentes deverão ter eles próprios uma conceção correta de criatividade e da sua importância para a formação superior dos alunos, o que nem sempre acontece (Edwards, McGoldrick, \& Oliver, 2007). Deverão, assim, ser agentes de mudança no 
sentido de práticas mais próximas da promoção de uma resolução criativa de problemas, como foi comentado na introdução deste artigo, para que a universidade esteja mais próxima do futuro (Miller \& Dumford, 2014). Mais investigação (nomeadamente qualitativa) sobre como o ensino superior vive ou não vive - criatividade é ainda fundamental, nomeadamente para entender em profundidade a $\mathrm{VOz}$ dos alunos e poder assim diagnosticar lacunas e potencialidades.

\section{Referências}

Alencar, E. M. L. S. (2001). Obstacles to personal creativity among university students. Gifted Education International, 15(2), 133-140.

Alencar, E. M. L. S., \& Fleith, D. S. (2001). Percepção de professores e estudantes universitários quanto ao estímulo à criatividade: Um estudo comparativo (Relatório de pesquisa). Brasília: Conselho Nacional de Desenvolvimento Científico e Tecnológico.

Alencar, E. M. L. S., Fleith, D., \& Martinez, A. M. (2003). Obstacles to personal creativity between brasilian and mexican university students: A comparative study. Journal of Creative Behaviour, 31, 179-192.

Baer, J. (2010). Is creativity domain specific? In J. Kaufman \& R. J. Sternberg (Eds.), The Cambridge handbook of creativity (pp. 321-341). New York: Cambridge University Press.

Barbot, B., Besançon, M., \& Lubart, T. (2011). Assessing creativity in the classroom. The Open Education Journal, 4, 58-66.

Balchim, T. (2007). Evaluating creativity through creative thinking. In N. Jackson, M. Oliver, M. Shaw, \& J. Wisdom (Eds.), Developing creativity in higher education (pp. 173-182). New York: Routledge.

Barak, M. (2009). Idea focusing versus idea generating: A course for teachers of inventive problem solving. Innovations in Education and Teaching International, 46, 345-356.

Caleo, S., \& Heilman, M. (2014). Is this a man's world? Obstacles to women's success in male-typed domains. In R. J. Burke \& D. Major (Eds.), Gender in organizations: Are men allies or adversaries to women's career advancement? (pp. 217-233). Northampton, MA: Edward Elgar Publishing.

Caniels, M. C. J. (2013). Organizing creativity: Creativity and innovation under constraints. Creativity and Innovation Management, 22(1), 100-102.

Chen, J-K., \& Chen, L-S. (2012). Critical creativity criteria for students in higher education: Taking the interrelationship effect among dimensions into account. Quality \& Quantity, 46, 1057-1075. doi: 10.1007/s11135-011-9448-7

Clegg, P. (2008). Creativity and critical thinking in the globalised university. Innovations in Education and Teaching International, 45(3), 219-226. 
Craft, A. (2005). Creativity in schools: Tensions and dilemmas. London, UK: Routledge.

Craft, A. (2007). Creativity in schools. In N. Jackson, M. Oliver, M. Shaw, \& J. Wisdom (Eds.), Developing creativity in higher education (pp. 19-28). New York: Routledge.

Cropley, A. (2009). Creativity in education and learning: A guide for teachers and educators. New York: Routledge.

Cropley, A., \& Cropley, D. (2009). Fostering creativity: A diagnostic approach for higher education and organizations. Cresskill, NJ: Hampton Press.

Davis, M. A. (2009). Understanding the relationship between mood and creativity: A meta-analysis. Organizational Behaviour and Human Decision Processes, 108(1), 25-38.

Deverell, A., \& Moore, S. (2014). Realising creativity in teaching and learning: The potential role of organizational legitimacy and increased dialogue. Innovations in Education and Teaching International, 51(2), 164-174.

Dineen, R. (2007). Views from the folk face: Lecturers' and students' perspectives on the development of creativity in art and design. In N. Jackson, M. Oliver, M. Shaw, \& J. Wisdom (Eds.), Developing creativity in higher education (pp. 109117). New York: Routledge.

Edwards, M., McGoldrick, C., \& Oliver, M. (2007). Creativity and curricula in higher education: Academic's perspectives. In N. Jackson, M. Oliver, M. Shaw, \& J. Wisdom (Eds.), Developing creativity in higher education (pp. 59-73). New York: Routledge.

Florida, R. (2002). The rise of the creative class: And how it's transforming work, leisure, community and everyday life. Annandale, Australia: Pluto Press.

Florida, R. (2005). The flight of the creative class: The new global competition for talent. Liberal Education, 92(3), 22-29.

Gibson, R. (2010). The art of creative teaching: Implications for higher education. Teaching on Higher Education, 15(5), 607-613.

Guilford, J. P. (1950). Creativity. American Psychologist, 5, 444-454.

Gralewski, J., \& Karwowski, M. (2013). Polite girls and creative boys? Student's gender moderates accuracy of teacher's ratings of creativity. The Journal of Creative Behaviour, 47(4), 290-304.

Hargreaves, J. (2008). Risk: The ethics of a creative curriculum. Innovations in Education and Teaching International, 45, 227-234.

Hennessey, B., \& Amabile, T. (2010). Creativity. Annual Review of Psychology, 61, 569-598.

Hosseini, A. (2011). University student's evaluation of creative education in universities and their impact on their learning. Procedia - Social and Behavioural Sciences, 15, 1806-1812.

Isaksen, S., \& Hakkermans, H. (2011). Creative climate: A leadership lever for innovation. Journal of Creative Behaviour, 45(3), 161-187.

Jackson, N. (2007). Making sense of creativity in higher education. In N. Jackson, M. Oliver, M. Shaw, \& J. Wisdom (Eds.), Developing creativity in higher education (pp. 197-215). New York: Routledge. 
Jackson, N., \& Sinclair, C. (2007). Developing students' creativity: Searching for an appropriate pedagogy. In N. Jackson, M. Oliver, M. Shaw, \& J. Wisdom (Eds.), Developing creativity in higher education (pp. 118-141). New York: Routledge.

Jackson, N., Oliver, M., Shaw, M., \& Wisdom, J. (Eds.). (2007). Developing creativity in higher education. New York: Routledge.

Kemmelmeier, M., \& Walton, A. P. (2012). Creativity in its social context: The interplay of organizational norms, situational threat, and gender. Creativity Research Journal, 24(2/3), 208-219.

Kim, K. H., \& Hull, M. F. (2012). Creative personality and intercreative environment for high school dropouts. Creativity Research Journal, 24, 169-176.

Kleiman, P. (2008). Towards transformation: Conceptions of creativity in higher education. Innovations in Education and Teaching International, 45, 209-217.

Leadbeater, C. (2000). The weightless society: Living in the new economic bubble. New York: Texere.

Lubart, T., \& Zenasni, F. (2010). A new look at creative giftedness. Gifted and Talented International, 25, 53-57.

Ma, H.-H. (2006). A synthetic analysis of the effectiveness of single components and packages in creativity training programs. Creativity Research Journal, 18, 435446.

MacLaren, I. (2012). The contradictions of policy and practice: Creativity in higher education. London Review of Education, 10, 159-172.

Masetto, M. (Ed.). (2012). Inovação no ensino superior. São Paulo: Edições Loyola.

McWilliam, E. (2008). Unlearning how to teach. Innovations in Education and Teaching International, 45, 263-269.

McWilliam, E., Hearn, G., \& Haseman, B. (2008). Transdisciplinarity for creative futures: What barriers and opportunities? Innovations in Education and Teaching International, 45, 247- 253.

Miller, A. L., \& Dumford, A. D. (2014). Creative cognitive processes in Higher Education. The Journal of Creative Behaviour, 48, 1-17.

Montuori, A. (2011). Beyond postnormal times: The future of creativity and the creativity of futures. Futures, 43(2), 221-117.

Morais, M. F. (2001). Definição e avaliação da criatividade. Braga: Universidade do Minho.

Morais, M. F. (2013). Creativity: Challenges to a key-concept for the twenty-first century. In A. Antonietti, B. Colombo, \& D. Memmert (Eds.), Psychology of creativity: Advances in theory, research and application (pp. 3-19). New York: NOVA Publishing.

Morais, M. F., Almeida, L. S., \& Azevedo, I. (2014). Criatividade e práticas docentes no Ensino Superior: Como pensam os alunos de áreas curriculares diferentes? Revista AMAZônica, 12(2), 97-126.

Morais, M. F., Almeida, L. S., Azevedo, I., Alencar, E. M. L. S., \& Fleith, D. S. (2014). Validação portuguesa do Inventário de Práticas Docentes na Educação Superior. Avaliação Psicológica, 13(2), 167-175. 
Moscovici, S. (2003). Representações sociais: Investigações em psicologia social. Petrópolis, RJ: Editora Vozes.

Nordstrom, K., \& Korpelainen, P. (2011). Creativity and inspiration for problem solving in engineering education. Teaching in Higher Education, 16(4), 439-450. doi: $10.1080 / 13562517$

Oliver, M., Shah, S., McGoldrick, C., \& Edwards, M. (2007). Student's experiences of creativity. In N. Jackson, M. Oliver, M. Shaw, \& J. Wisdom (Eds.), Developing creativity in higher education (pp. 43-58). New York: Routledge.

Oliveira, Z. M. F., \& Alencar, E. M. L. S. (2007). Criatividade na formação e atuação do professor do curso de Letras. Psicologia Escolar e Educacional, 11, 223-237.

Renzulli, J. S. (2005). The three-ring conception of giftedness: A developmental model for promoting creative productivity. In R. J. Sternberg \& J. Davidson (Eds.), Conceptions of giftedness (pp. 217-245). Boston, MA: Cambridge University Press.

Pachucki, M. A., Lena, J. C., \& Tepper, S. J. (2010). Creativity narratives among college students: Sociability and everyday creativity. The Sociological Quarterly, 51, 122-149.

Pink, D. H. (2005). A whole new mind. New York: Penguin.

Ribeiro, R. A., \& Fleith, D. S. (2007). O estímulo à criatividade em cursos de licenciatura. Paidéia, 17, 403-416.

Runco, M. A. (2014). Creativity: Theories and themes - Research, development and practice. San Diego, CA: Academic Press.

Runco, M., \& Jager, G. (2012). The standard definition of creativity. Creativity Research Journal, 24(1), 92-96.

Sadeghi, A., \& Ofoghi, N. (2011). The psychological factors affecting student's creativity inside the class. Procedia - Social and Behavioural Sciences, 15, 263-270.

Sahlberg, P. (2011). The role of education in promoting creativity: Potential barriers and enabling factors. In R. Schenkel \& O. Quintin (Eds.), Measuring creativity (pp. 337-344). Brussels: The European Commission.

Sathler, T. C., \& Fleith, D. D. S. (2010). Incentives and barriers to creativity in the context of distance learning. Estudos de Psicologia (Campinas), 27(4), 457-466.

Shinnar, R. S., Giacomin, O., \& Janssen, F. (2012). Entrepreneurial perceptions and intentions: The role of gender and culture. Entrepreneurship Theory and Practice, 36, 465-493.

Slate, J., LaPrairie, K. N., Schulte, D. P., \& Onwuegbuzie, A. (2011). Views of effective college faculty: A mixed analysis. Assessment and Evaluation in Higher Education, 36, 331-346.

Simonton, D. K. (2012). Taking the U.S. patent office criteria seriously: A quantitative three-criterion creativity definition and its implications. Creativity Research Journal, 24, 97-106.

Smith-Bingham, R. (2007). Public policy, innovation and the need for creativity In N. Jackson, M. Oliver, M. Shaw, \& J. Wisdom (Eds.), Developing creativity in higher education (pp. 10-18) New York: Routledge. 
Sternberg, R. J. (2015). Wisdom, intelligence and creativity synthesized. Cambridge, MA: Cambridge University Press.

Tosey, P. (2007). Interfering with the interference: An emergent perspective on creativity in higher education. In N. Jackson, M. Oliver, M. Shaw, \& J. Wisdom (Eds.), Developing creativity in higher education (pp. 29-42). New York: Routledge.

Walker, C., \& Gleaves, A. (2008). An exploration of students' perceptions and understandings of creativity as an assessment criterion in undergraduate-level studies within higher education. Irish Educational Studies, 27, 41-54.

Wood, D., \& Bilsborow, C. (2014). I am not a person with a creative mind: Facilitating creativity in the undergraduate curriculum through a design-based research approach. Electronic Journal of e-Learning, 12(1), 111-125. 


\title{
PERCEPTIONS ABOUT CREATIVITY: A STUDY WITH UNIVERSITY STUDENTS
}

\begin{abstract}
In today's world, the University has a crucial role in the education of citizens in order to innovate. Creativity is thus a concept to value in higher education, but that valuation implies changes in the educational practices. A relevant source of information in order to promote creative skills in college students is to gather what they think about those skills. Through the questionnaire "University and Creative Skills" the perceptions of 582 Portuguese university students about the conceptualization and valorization of creativity in the academic contexts were analyzed. The perceptions were analyzed according to the students' curriculum area and gender. Data suggest significant statistical differences in function of both variables. The results allow reflections towards further developments of this study but also point directions to reinforce deliberate educational practices in this level of education.
\end{abstract}

Keywords

Creativity; Higher Education; College students; Perceptions

\section{PERCEPCIONES ACERCA DE CREATIVIDAD: ESTUDIO CON ALUMNADO UNIVERSITARIO}

Resumen

En el mundo actual la universidad tiene un papel crucial en la formación de ciudadanos capaces de innovar. La creatividad es, pues, un concepto a valorar en la educación superior, pero esta valoración implica cambios en la vida cotidiana educativa. Una fuente de información relevante para la promoción de las habilidades creativas en los estudiantes universitarios es auscultar lo que piensan acerca de estas habilidades. En este sentido, a partir del cuestionario "Universidad y Competencias Creativas", se analizaron las percepciones de 582 estudiantes de una universidad portuguesa acerca de la 
conceptualización y de la valoración de la creatividad en el contexto académico. Las percepciones se analizaron de acuerdo con el área curricular de formación y el género, encontrando diferencias estadísticamente significativas en función de ambas las variables. Los resultados permiten reflexiones hacia una mayor profundización de este estudio, pero también señalan orientaciones para cuidados y refuerzos sobre las prácticas educativas en este nivel de enseñanza.

Palabras-clave

Creatividad; Enseñanza Superior; Alumnado universitario; Percepciones

Recebido em setembro/2015 Aceite para publicação em março/2016

i Centro de Investigação em Educação, Instituto de Educação, Universidade do Minho, Portugal. ii Centro de Investigação em Educação, Instituto de Educação, Universidade do Minho, Portugal.

Toda a correspondência relativa a este artigo deve ser enviada para: Maria de Fátima Morais, Instituto de Educação, Universidade do Minho, Campus de Gualtar, 4710-057 Braga. E-mail: famorais@ie.uminho.pt 